\title{
Correction: Modelling focused electron beam induced deposi- tion beyond Langmuir adsorption
}

\author{
Dédalo Sanz-Hernández and Amalio Fernández-Pacheco*
}

\section{Correction}

\section{Address:}

Cavendish Laboratory, University of Cambridge, JJ Thomson

Cambridge, CB3 OHE, United Kingdom

Email:

Amalio Fernández-Pacheco* - af457@cam.ac.uk

* Corresponding author

Keywords:

adsorption isotherm theory; BET model; continuum model; focused

electron beam induced deposition; 3D nanoprinting; Langmuir model
Beilstein J. Nanotechnol. 2017, 8, 2591.

doi:10.3762/bjnano.8.259

Received: 17 November 2017

Accepted: 24 November 2017

Published: 05 December 2017

This article is part of the Thematic Series "Chemistry for electron-induced nanofabrication".

Guest Editor: P. Swiderek

C 2017 Sanz-Hernández and Fernández-Pacheco; licensee Beilstein-Institut.

License and terms: see end of document.

This correction refers to Beilstein J. Nanotechnol. 2017, 8, 2151-2161. doi:10.3762/bjnano.8.214

The originally published Equation 1 contains a mistake. The theta factor in the second right term is missing. The correct Equation 1 is

$$
\frac{\partial \theta}{\partial t}=\frac{s F}{N_{0}}(1-\theta)-v_{0} e^{\frac{-E}{k_{\mathrm{B}} T}} \theta-\sigma J \theta
$$

\section{License and Terms}

This is an Open Access article under the terms of the Creative Commons Attribution License (http://creativecommons.org/licenses/by/4.0), which permits unrestricted use, distribution, and reproduction in any medium, provided the original work is properly cited.

The license is subject to the Beilstein Journal of Nanotechnology terms and conditions: (http://www.beilstein-journals.org/bjnano)

The definitive version of this article is the electronic one which can be found at: doi:10.3762/bjnano.8.259 